\title{
Evaluation of the virulence of Sclerotium rolfsii isolates on Arachis hypogaea and screening for resistant genotypes in greenhouse conditions
}

\author{
A.A. Eslami', S.A. Khodaparast', S. Mousanejad'", F. Padasht Dehkaei²
}

Summary Sclerotium rolfsii is a soil borne pathogen responsible for root and stem rot on a wide range of crops. This study was conducted to identify the virulence of different $S$. rolfsii isolates on a susceptible local peanut germplasm and determine the resistance of 20 peanut genotypes to the most virulent isolate and also the relationship between virulence and mycelial compatibility groups (MCGs). Seventy eight isolates of this fungus from 10 host plants and six known MCGs were used in the experiment. The experiment was done in greenhouse conditions $\left(25 \pm 5^{\circ} \mathrm{C}\right)$ using a complete randomized block design with three replications. Pots containing sterile soil $(\mathrm{pH}=6.7)$ were inoculated with barley seeds colonized by each isolate separately before being seeded with the peanut germplasm. Disease severity was assessed by scoring the wilting, yellowing or death of plants, mycelia or sclerotia production on the soil surface or on plant stem, stem area affected (\%) and stem lesion length, at the stage of plant maturity. Also, shoot wet weight and plant height were recorded at this stage. According to the results of the pathogenicity tests, all of the isolates were virulent on the susceptible peanut germplasm and the virulence differed significantly between the isolates $(P \leq 0.01)$. There was no relationship between the virulence of the five groups of isolates identified in the present study and the MCGs. The peanut genotype 140, which was better than the others based on seed size, plant height and the canopy size, was also the most resistant one.

Additional keywords: diversity, groundnut, pathogenicity, southern blight, stem rot

\section{Introduction}

Sclerotium rolfsii Sacc. (teleomorph: Athelia rolfsii (Curzi) Tu \& Kimbrough) is one of those soil borne plant pathogenic fungi that are prevalent in warm temperate and subtropical regions of the world (Punja et al., 1984). This pathogen has a host range of over 500 plant species mostly of dicotyledonous plants. A wide range of symptoms are produced by this pathogen on its hosts including crown and root rot, stem canker and damping-off and resulting diseases called southern wilt, blight or stem rot (Punja, 1985). The pathogen is of great im-

\footnotetext{
Department of Plant Protection, Faculty of Agricultural Sciences, University of Guilan, P.O. Box: 41635-1314, Rasht, Iran

2 Department of Plant Protection, Rice Research Institute of Iran, P.O. Box: 1658, Rasht, Iran

* Corresponding author: mousanejad@guilan.ac.ir smousanejad@yahoo.com
}

portance especially when the disease severity is high in the fields. The crop loss may be between $10-25 \%$ or even more than $81 \%$ in some fields (Mehan et al., 1995).

Groundnut or peanut (Arachis hypogaea L.) is an annual legume crop cultivated in more than 80 countries in the tropics, subtropics and warm temperate zones (Hammons, 1994). It is a major source of edible oil, vitamins and amino acids and is used extensively for feed and food (Savage and Keenan, 1994). Groundnut is also a main crop in Guilan province of Iran with about 3500 hectares cultivation area.

Southern blight, stem rot or white mould, caused by S. rolfsii, is one of the most important diseases of peanut. The disease appears in peanut growing areas and causes great yield losses when climatic conditions, such as soil temperature and humidity, are favorable for fungal development and the dis- 
ease incidence is high (Kolte, 1984; Le, 2004; Nguyen, 2004).

Sclerotium rolfsii overwinters as mycelium or sclerotia in infected plant tissues and soil. Under favorable conditions, hyphae or germinating sclerotia infect the plant and subsequently colonize and invade the root and stem tissue with typical silky white mycelium (Brewster, 2001). Infected plants become yellow and then wilt, the collar root turns brown and rots. In groundnut, S. rolfsii also infects the pegs and pods, leading to yield losses.

Sclerotium rolfsii is difficult to control by physical and cultural practices due to its wide host range of over 500 plant species (Aycock, 1966; Punja, 1985) and persistent sclerotia (Lakpale, 2007; Punja, 1985). To successfully implement management practices (e.g., chemical and biological) to control S. rolfsii, knowledge of the distribution and diversity especially in pathogenicity and virulence of the pathogen is essential.

Branch and Brenneman (1999) evaluated the resistance of mass-selected populations derived from combinations of crosses among two resistant and two susceptible peanut cultivars. Fery and Dukes sr. (2002) determined the cowpea resistance to $S$. rolfsii. There was significant variability in cowpea germplasm for resistance to southern blight. In another study (Flores-Moctezuma et al., 2006), two onion isolates of S. rolfsii were inoculated to 51 plant species and disease severity levels were determined. Subsequently, 12 out of 51 plant species were selected for the determination of pathogenic reaction to 20 isolates of S. rolfsii from different regions. Onion isolates produced variable levels of disease severity for half of the plants tested. Five plant species were susceptible or highly susceptible to all isolates.

Eleven sugar beet genotypes were evaluated at National Agricultural Research Center, Islamabad, Pakistan, during the year 2009 for their resistance against root rot caused by S. rolfsii (Farooq et al., 2011). Inoculation of eleven genotypes with $S$. rolfsii exhibited resistant response only in SD-PAK-09/07 and moderate resistance in SD-PAK-07/071.
The results of a recent study showed that S. rolfsii isolates originating from groundnut, tomato and taro were all pathogenic on groundnut, but displayed substantial diversity of various genetic and phenotypic traits, including mycelial compatibility, growth rate, and sclerotial characteristics (Le et al., 2012).

The aim of this study was to identify the virulence of different S. rolfsii isolates on a susceptible local peanut germplasm and determine the resistance of twenty peanut genotypes to the most virulent isolate and also the relationship between virulence and mycelial compatibility groups (MCGs).

\section{Materials and Methods}

\section{Isolates virulence determination}

Seventy eight isolates of $S$. rolfsii from ten different hosts in Guilan province with known MCGs (Mehri et al., 2013) were applied for inoculation of a local susceptible peanut germplasm in greenhouse conditions (Table 1).

Barley seeds were boiled in distilled water for twenty minutes and then $12 \mathrm{gr}$ of seeds were added to each $100 \mathrm{ml}$ Erlenmeyer flask and autoclaved twice at $121^{\circ} \mathrm{C}$ and 1.5 atmospheres for thirty minutes. For each isolate a $5 \mathrm{~mm}$ disk of growing fungus on PDA medium was transferred to the Erlenmeyer flask containing sterilized barley seeds and the cultures were maintained in the growth chamber $\left(27 \pm 1^{\circ} \mathrm{C}\right)$ (Sennoi et al., 2010).

The applied soil (1:1:2 clay, compost, sand, $\mathrm{pH}=6.7$ ) was autoclaved at $121^{\circ} \mathrm{C}$ and 1.5 atmospheres for thirty minutes and added to the pots with $500 \mathrm{gr}$ soil capacity. Seeds of a local susceptible peanut germplasm were sterilized with Sodium Hypochlorite $1 \%$ solution for three minutes and rinsed with sterilized distilled water three times, then soaked in sterilized distilled water. The peanut seeds were placed in a moist chamber at $25 \pm 5^{\circ} \mathrm{C}$ for $72 \mathrm{~h}$ to germinate.

When the mycelium covered all the barley seeds and enough sclerotia were formed, each pot was inoculated with thirty infected barley seeds and the seeds were covered 
Table 1. Sclerotium rolfsii isolates from different MCGs and host plants.

\begin{tabular}{|c|c|c|c|c|c|c|c|c|c|c|c|}
\hline MCGs & $\begin{array}{l}\bar{d} \\
\stackrel{0}{0} \\
\overline{0} \\
\varrho\end{array}$ & 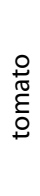 & $\begin{array}{l}\frac{c}{\tilde{y}} \\
\frac{\sigma}{\sigma} \\
\frac{\sigma}{n}\end{array}$ & $\begin{array}{l}\text { ฮ్ } \\
\text { ֶి }\end{array}$ & 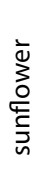 & $\begin{array}{l}\frac{\tilde{c}}{0} \\
\frac{0}{0} \\
\text { Oे } \\
\text { d }\end{array}$ & 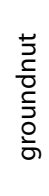 & 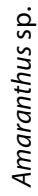 & $\begin{array}{l}\frac{\dot{0}}{0} \\
\frac{0}{0} \\
\frac{0}{2} \\
\frac{0}{3} \\
\frac{2}{4}\end{array}$ & 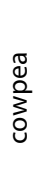 & 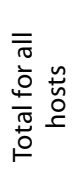 \\
\hline MCG1 & 13 & 0 & 0 & 13 & 2 & 0 & 5 & 2 & 0 & 1 & 36 \\
\hline MCG2 & 1 & 0 & 0 & 1 & 0 & 0 & 0 & 0 & 0 & 0 & 2 \\
\hline MCG3 & 3 & 5 & 1 & 3 & 0 & 2 & 15 & 0 & 2 & 1 & 32 \\
\hline MCG4 & 0 & 0 & 0 & 3 & 0 & 1 & 0 & 0 & 0 & 0 & 4 \\
\hline MCG5 & 2 & 0 & 0 & 1 & 0 & 0 & 0 & 0 & 0 & 0 & 3 \\
\hline MCG6 & 0 & 0 & 0 & 1 & 0 & 0 & 0 & 0 & 0 & 0 & 1 \\
\hline $\begin{array}{c}\text { Total for all } \\
\text { MCGs }\end{array}$ & 19 & 5 & 1 & 22 & 2 & 3 & 20 & 2 & 2 & 2 & 78 \\
\hline
\end{tabular}

with a thin soil layer. The experiment was done as a complete randomized block design with three replications. There were two controls for each treatment including pots inoculated with thirty sterile barley seeds. After establishment of the fungus in soil, the germinated peanut seeds were cultured into pots (one seed per pot) (Toribio et al., 1992). The pots were maintained in greenhouse conditions at $25 \pm 5^{\circ} \mathrm{C}$ (Erkilic et al., 2006). The pots were irrigated based on seedlings need for prevention of water stress (Flores-Moctezuma et al., 2006; Sennoi et al., 2010).

Disease symptoms were monitored daily from one week after peanut seeding, when the symptoms were observed. At the plants maturity (about 6 weeks after seeding), all the plants were uprooted at the same time and the roots were washed in running tap water to remove soil particles (Yaqub and Shahzad, 2005).

Disease severity was assessed by scoring the plant wilting, yellowing or death, mycelia or sclerotia production on the soil surface or on plant stem, stem area affected (\%) and lesion length. Disease severity index was calculated for each treatment using these scores according to the Townsend-Heuberger formula (Erkilic et al., 2006) as bellow:

$$
D S(\%)=\frac{\sum(n \times v)}{N \times V} \times 100
$$

Where,

$\mathrm{n}$ : degree of infection according to the scale (Le et al., 2012),

v: number of seedlings per category,

$\mathrm{N}$ : total number of seedlings were screened and

$\mathrm{V}$ : highest degree of infection.

Also, shoot wet weight and plant height were recorded at this stage. The data were analyzed by the one-way ANOVA followed by Tukey's multiple range test for mean comparison using SAS v. 9.0 software.

\section{Peanut genotypes resistance evaluation}

One of the most virulent isolates of $S$. rolfsii on the tested germplasm was used for evaluation of the twenty peanut genotypes resistance in greenhouse conditions as completely randomized design. The germinated peanut seeds and the infected barley seeds were prepared in the same way as mentioned in isolates virulence determination experiment. The germinated peanut seeds were cultured into pots and two weeks after seeding, the seedlings were inoculated with three infected barley seeds (Sennoi et al., 2010). Each cultivar was also inoculated by three sterile barley seeds as control treatment. The genotype resistance was evaluated one month after seeding, based on the scale and characteristics mentioned before (Le et al., 2012). 


\section{Results}

S. rolfsii isolates covered the barley seeds 2-3 weeks after inoculation as white mycelia. In the isolates virulence determination experiment, two weeks after seeding of peanut germplasm, disease symptoms were observed on peanut seedling stems as water soaked spots which turned to rot soon (Figure 1). These spots resulted in wilting and death of plants during their maturation. The fungus mycelia extended around the stems and on the soil surface. Sclerotia were also observed on these mycelia.

All of the isolates were virulent on tested peanut germplasm and the virulence was significantly different within the isolates at $\mathrm{p} \leq 0.01$ (Figures 2 and 3). There were significant differences between the shoot wet weight and plant height in the treatments $(p \leq 0.01)$. The plants which were inoculated with isolates 8 and 73 were the highest $(33.5 \mathrm{~cm})$ and those inoculated with isolate 64 were the shortest plants $(7.33 \mathrm{~cm})$. There was a significant negative correlation between plant height and disease severity in$\operatorname{dex}(\mathrm{DSI})$. The higher was the DSI, the shorter was the plant height (Table 2).

Stem and root rot resulting from this disease reduced the shoot wet weight. There was a significant negative correlation between shoot wet weight and DSI. The higher was the DSI, the less was the shoot weight.

Variance analysis of the data related to

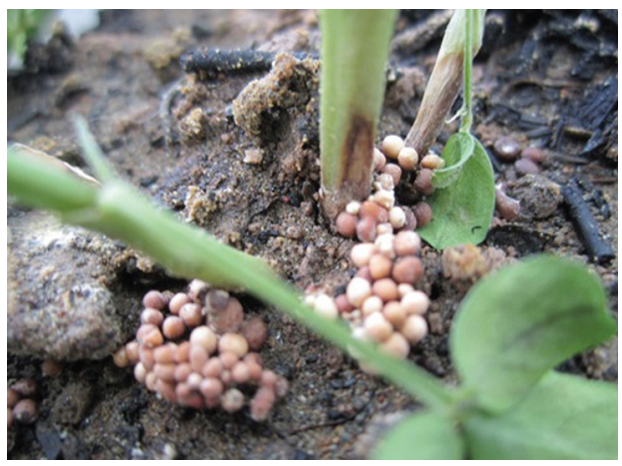

Figure 1. Stem lesion caused by a virulent isolate of Sclerotium rolfsii on a susceptible local peanut germplasm. The sclerotia produced on the infected stem and on the soil surface. stem lesion length showed significant difference between the isolates $(p \leq 0.01)$. Isolate 73 caused the shortest lesion $(2.35 \mathrm{~mm})$ and isolate 53 caused the longest one $(100.56 \mathrm{~mm})$.

Stem area affected (\%) shows the proportion of the lesion width to the healthy stem circumference. For the isolates $1,6,38$, $42,44,47,53,57,64,69$ and 70 this proportion was $100 \%$. The least amount was for the isolates 8 (15\%).

Disease symptoms occurrence in an infected plant can be compared with a healthy control plant and this criterion can be expressed as percent in an overview. Thus, the symptoms like wilting, yellowing of the entire leaves or only the lower leaves, occurrence of the lesions and crown infection were evaluated. This criterion was $100 \%$ for isolates 1, 6, 38, 42, 44, 47, 53, 57, 64, 69 and 70 and $16.66 \%$ for isolate 8 (Figure 3 ).

Based on the correlation analysis results, there was a significant correlation within all measured criteria at $p \leq 0.01$ (Table 2). There was a significant positive correlation between percent of symptoms occurrence, DSI, stem lesion length and stem area affected (\%), but a negative correlation between these mentioned criteria and plant height and shoot wet weight. The greater was the amount of lesion length or stem area affected, the higher were the symptoms occurrence and DSI, the less the plant height and wet weight and therefore the more virulent the tested isolate. When the plants had been infected by the fungus especially in their seedling stage, the seedlings lost their normal growth and the final plant height decreased compared to uninfected control plants. The isolates which were more virulent also decreased the peanut seedlings emergence rate more.

The 78 tested isolates in this study were significantly different in their virulence on the tested peanut germplasm and were divided to five groups based on their virulence $(P \leq 0.01)$. The isolates $38,6,1,42,44,47$, $53,57,64,69$ and 70 were the most virulent and the isolates 8 and 73 were the least virulent ones. Considering the calculated DSI for each isolate, the tested peanut germplasm reaction to these isolates was expressed as 

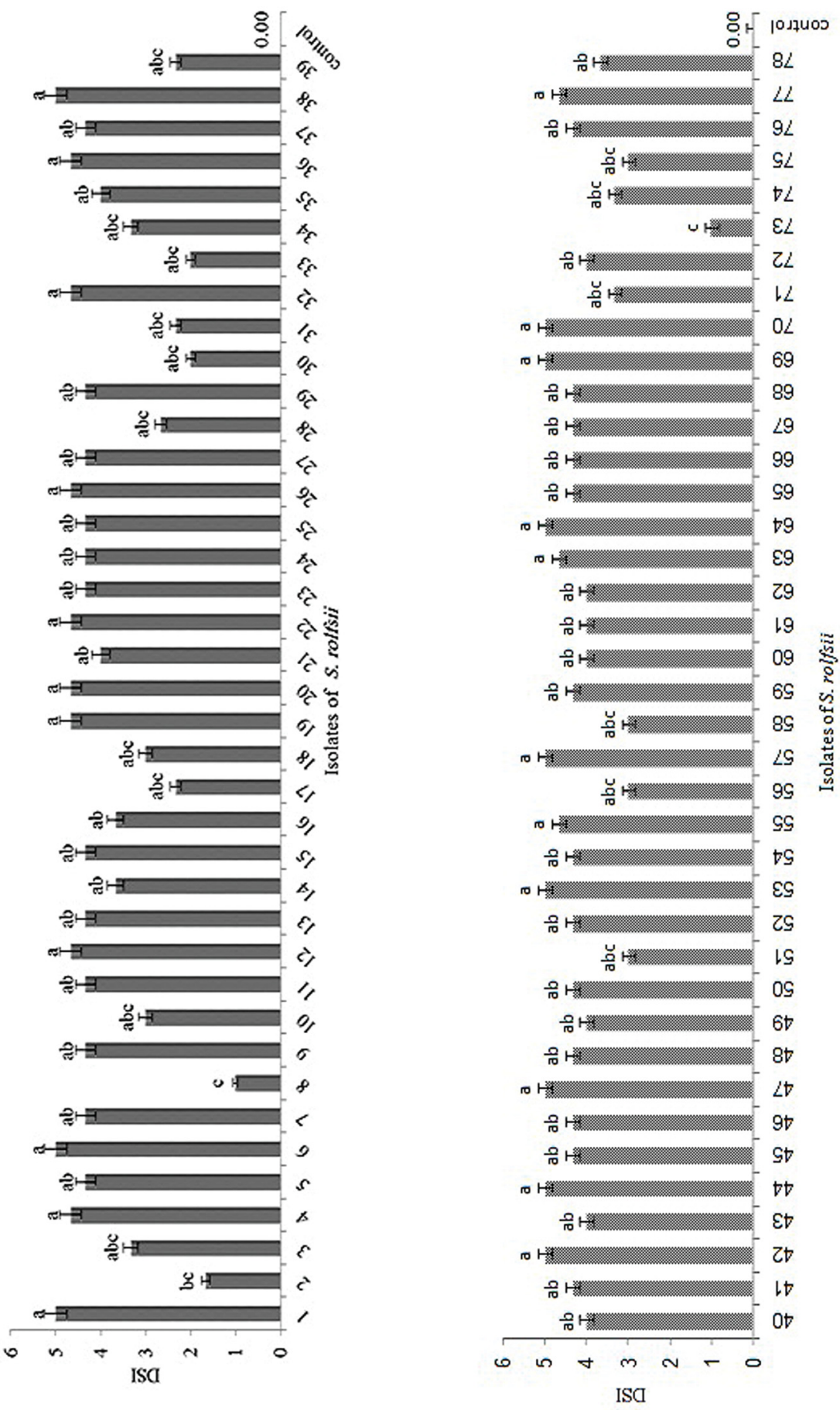


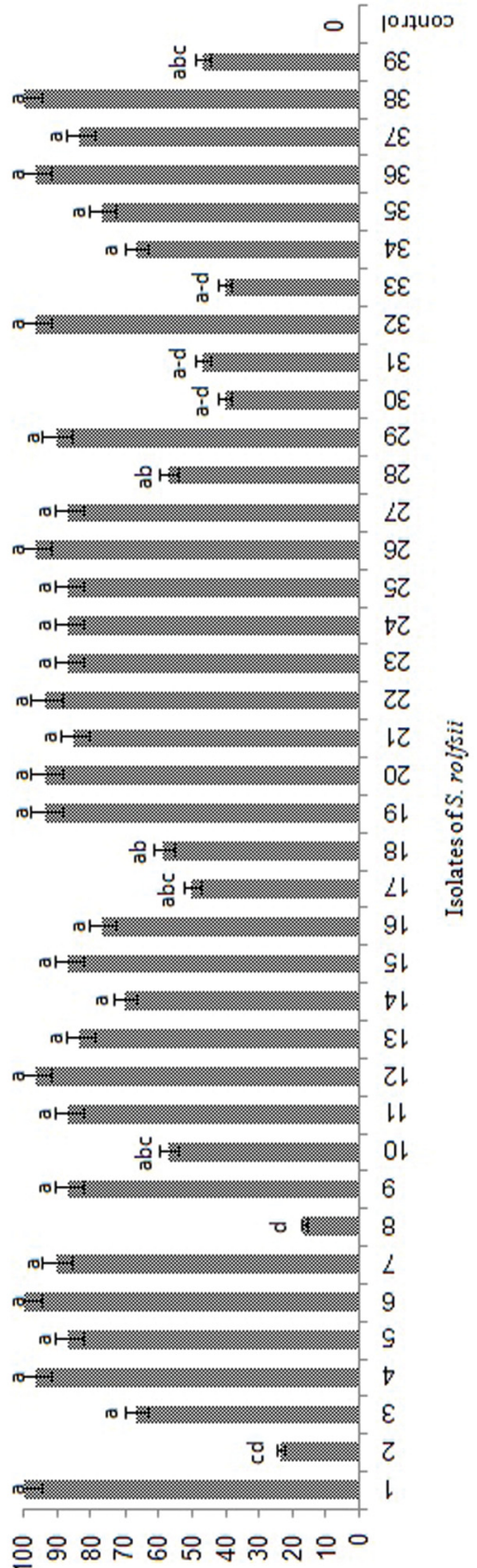

อวนว.เmองอ

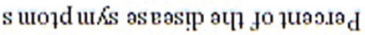

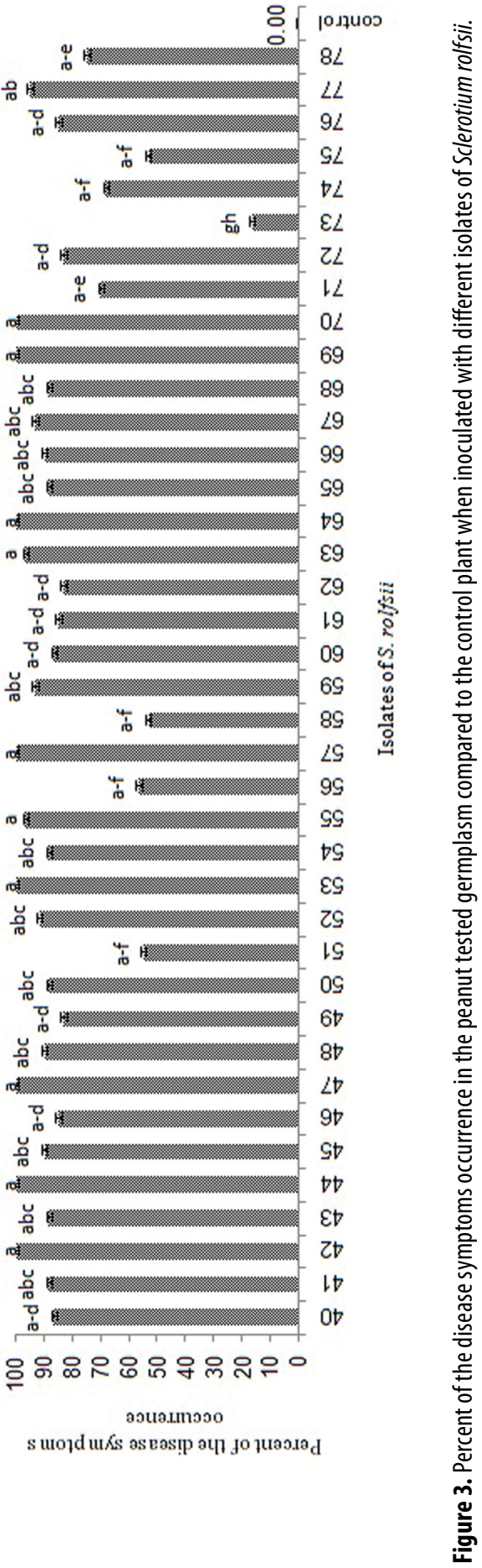

(c) Benaki Phytopathological Institute 
Table 2. Correlation between the measured criteria in the Sclerotium rolfsii isolates virulence evaluation test.

\begin{tabular}{|c|c|c|c|c|c|c|c|}
\hline & & 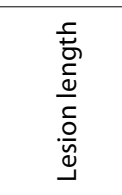 & 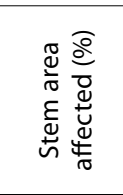 & 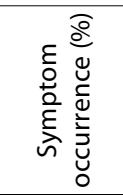 & $\overline{\check{\Lambda}}$ & 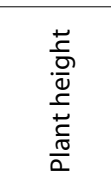 & 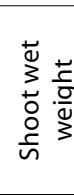 \\
\hline Lesion length & $\begin{array}{c}\text { Pearson } \\
\text { Correlation } \\
\mathrm{N}\end{array}$ & $\begin{array}{c}1 \\
78\end{array}$ & & & & & \\
\hline $\begin{array}{l}\text { Stem area } \\
\text { affected (\%) }\end{array}$ & $\begin{array}{c}\text { Pearson } \\
\text { Correlation } \\
\mathrm{N}\end{array}$ & $\begin{array}{c}0.810^{* *} \\
78\end{array}$ & $\begin{array}{c}1 \\
78 \\
\end{array}$ & & & & \\
\hline $\begin{array}{c}\text { Symptom } \\
\text { occurrence (\%) }\end{array}$ & $\begin{array}{c}\text { Pearson } \\
\text { Correlation } \\
\mathrm{N}\end{array}$ & $\begin{array}{c}0.815^{* *} \\
78\end{array}$ & $\begin{array}{c}0.981^{* *} \\
78\end{array}$ & $\begin{array}{c}1 \\
78\end{array}$ & & & \\
\hline DSI & $\begin{array}{c}\text { Pearson } \\
\text { Correlation } \\
\mathrm{N}\end{array}$ & $\begin{array}{c}0.831^{* *} \\
78 \\
\end{array}$ & $\begin{array}{c}0.989^{* *} \\
78 \\
\end{array}$ & $\begin{array}{c}0.990^{* *} \\
78 \\
\end{array}$ & $\begin{array}{c}1 \\
78 \\
\end{array}$ & & \\
\hline Plant height & $\begin{array}{c}\text { Pearson } \\
\text { Correlation } \\
\mathrm{N} \\
\end{array}$ & $\begin{array}{c}-0.730^{* *} \\
78\end{array}$ & $\begin{array}{c}-0.896^{* *} \\
78\end{array}$ & $\begin{array}{c}-0.894^{* *} \\
78\end{array}$ & $\begin{array}{c}-0.906^{* *} \\
78\end{array}$ & $\begin{array}{c}1 \\
78 \\
\end{array}$ & \\
\hline Shoot wet weight & $\begin{array}{c}\text { Pearson } \\
\text { Correlation } \\
\mathrm{N}\end{array}$ & $\begin{array}{c}-0.299^{* *} \\
78\end{array}$ & $\begin{array}{c}-0.404^{* *} \\
78\end{array}$ & $\begin{array}{c}-0.371^{* *} \\
78\end{array}$ & $\begin{array}{c}-0.396^{* *} \\
78\end{array}$ & $\begin{array}{c}0.349^{* *} \\
78\end{array}$ & $\begin{array}{c}1 \\
78 \\
\end{array}$ \\
\hline
\end{tabular}

$\mathrm{R}=$ resistant with scores of $0-2, \mathrm{MR}=$ moderately resistant with scores $2.1-3, \mathrm{~S}=$ susceptible with scores 3.1-4.99 or $\mathrm{HS}=$ highly susceptible with score 5 (Farooq et al., 2011; Flores-Moctezuma et al., 2006). The tested peanut germplasm was resistant, moderately resistant, susceptible and highly susceptible to $6.41,12.82,66.67$ and 14.1 percent of tested isolates, respectively.

The five identified groups in the tested isolates based on the virulence, overlapped to some extent with six MCGs identified for these isolates before (Mehri et al., 2013). For example, MCG4 only included 4 isolates and the tested peanut germplasm was susceptible to all of them. The MCG5 only had three members which caused susceptible or highly susceptible reaction on the tested germplasm. This overlap has not been observed for all MCGs and some of them included the isolates with different virulence.

Different peanut genotypes resistance to one of the most virulent isolates of S. rolfsii (isolate 53) was determined based on the scores and criteria mentioned above for isolates virulence evaluation. Variance analysis of the data showed that the genotypes were significantly different in their resistance to S. rolfsii. Considering the calculated DSI for each genotype (Figure 4 ), its reaction to the tested isolate was expressed as $\mathrm{R}=\mathrm{re}$ sistant with scores of $0-2, M R=$ moderately resistant with scores $2.1-3, \mathrm{~S}=$ susceptible with scores 3.1-4.99 or HS= highly susceptible with score 5 (Farooq et al., 2011; FloresMoctezuma et al., 2006).

The genotypes 140 and 183 were resistant to the tested isolate. The genotype 129 was moderately resistant and 137, 138, 193 and 208 were highly susceptible. All the other genotypes showed susceptible reaction. The genotypes 140 and 183 had the least amount of stem lesion length, stem area affection and disease symptom occurrence 


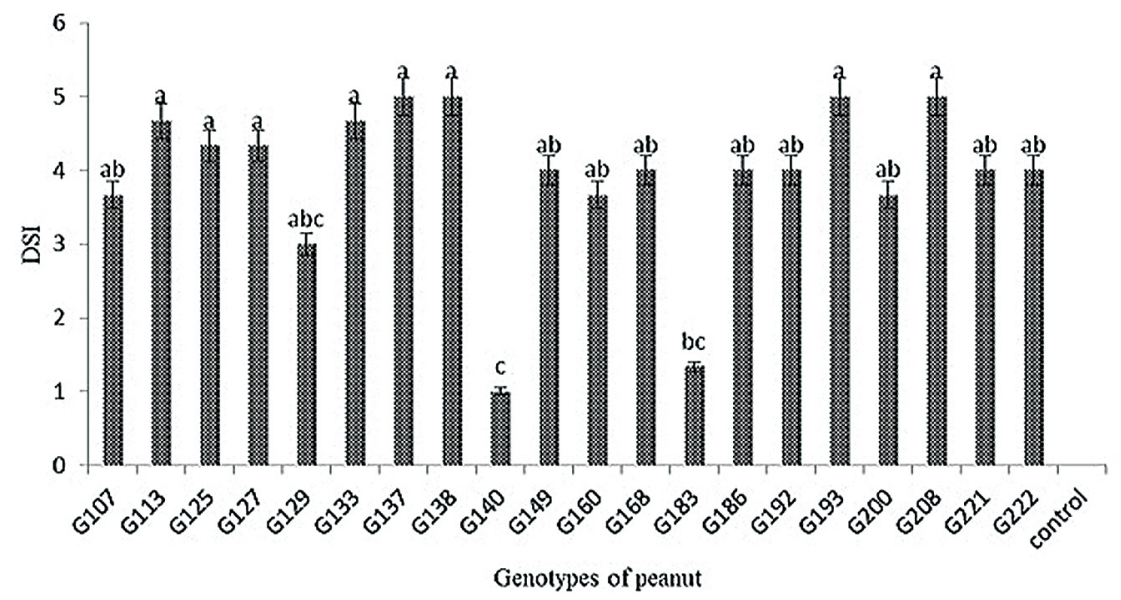

Figure 4. Disease severity index (DSI) for different peanut genotypes when inoculated with one of the most virulent isolates of Sclerotium rolfsii.

and the highest amount of height or shoot wet weight. No systemic infection symptoms such as yellowing or wilting were observed in these two genotypes.

\section{Discussion}

Based on our research results, the shoot wet weight and plant height decreased in different treatments related to the isolates virulence. Also, the isolates which were more virulent decreased the peanut seedlings emergence rate more. These results on isolates virulence evaluation were compatible with those achieved by Yaqub and Shahzad (2005) who evaluated the S. rolfsii isolates virulence on different host plants. Based on their study results, soil infestation with S. rolfsii caused a significant reduction in germination of sunflower, mungbean and sugar beet seeds as compared to control. Germination of tomato, sweet pumpkin, cabbage and cauliflower seeds were slightly reduced. The highest reduction in plant length, weight and shoot weight as compared to control was observed in sunflower and mungbean followed by sugar beet, tomato, sweet pumpkin and cabbage. Cauli- flower plants showed no effect of S. rolfsii infection on plant growth. S. rolfsii proved to be highly pathogenic on sunflower, mungbean and sugar beet, mildly pathogenic on tomato, lentil, sweet pumpkin and cabbage, and non-pathogenic on cauliflower plants in pot experiments in their study.

Our results related to isolates virulence and genotypes resistance differences are comparable with those in the study by Flores-Moctezuma et al. (2006), in which two onion isolates of $S$. rolfsii from the states of Morelos and Guanajuato, Mexico were inoculated to 51 plant species and disease severity levels were determined. Subsequently, 12 out of 51 plant species were selected for the determination of pathogenic reaction to 20 isolates of S. rolfsii from different regions of Mexico. Onion isolates from Morelos and Guanajuato produced variable levels of disease severity for half of the plants tested. Five plant species were susceptible or highly susceptible to all isolates. The remaining plants tested showed differential reactions to individual isolates, ranging from highly resistant to highly susceptible.

As already mentioned, the five identified groups in the tested isolates based on the virulence, overlapped to some extent 
with six MCGs identified for these isolates by Mehri et al. (2013). Harlton et al. (1995) found 49 MCG and 12 RFLP-ITS groups in a worldwide collection of $S$. rolfsii isolates and they did not find a correlation between MCG groups and pathogenicity. In our case, there was also no significant correlation between the isolates virulence and their geographical or host plant origin. In a random selection, not all the identified high virulent isolates had been isolated from peanut and some, which were isolated from peanut, were not virulent on the tested peanut local germplasm. These results were compatible with the results of research conducted by FloresMoctezuma et al. (2006) and Le et al. (2012).

Regarding the peanut genotypes resistance evaluation, most of the genotypes were susceptible to the selected most virulent isolate and the resistant reaction was observed only in few genotypes which showed no systemic infection symptoms such as yellowing or wilting. The results were similar to the results reported in other investigations (Farooq et al., 2011; Flores-Moctezuma et al., 2006; Yaqub and Shahzad, 2005).

In this investigation, disease severity was evaluated using several scoring methods like the plant wilting, yellowing or death, mycelia or sclerotia production on the soil surface or on plant stem, stem area affected (\%) and lesion length, shoot wet weight and plant height and also percent of the disease symptom occurrence. We finally concluded that stem area affection is a very useful criterion for the evaluation of isolates virulence or genotype resistance and stem lesion length is of second importance. The two resistant peanut genotypes to $S$. rolfsii identified in our study will be useful for the control of the white rot disease in the peanut fields and the reduction of the losses through the introduction of the genotypes in Guilan province, especially because the genotype 140 is better than the others based on seed size, plant height and the canopy.

The authors would like to thank University of Guilan (Deputy of Research) for its important technical support and Agriculture and Natural Resources Research Center of Guilan for preparation of peanut genotypes seeds.

\section{Literature Cited}

Aycock, R. 1966. Stem rot and other diseases caused by Sclerotium rolfsii. North Carolina Agricultural Experiment Station Technical Bulletin, 174, 202.

Branch, W.D. and Brenneman, T.B. 1999. Stem rot disease evaluation of mass-selected peanut populations. Crop Protection, 18: 127-130.

Brewster, V. 2001. Southern blight, Southern stem blight, White mold. APS net. Online publication.

Erkilic, A., Guven, B. and Akgul, D.S. 2006. Effects of some plant activators and plant materials on stem rot disease of peanut and pepper caused by Sclerotium rolfsii. Journal of Turkish Phytopathology, 35 (1-3), 15-28.

FAO. 2010. FAO Statistics Division. Online publication.

Farooq, M.A., Iqbal, U., Rasool, A., Zubair, M., Iqbal, S.M. and Ahmad, A. 2011. Evaluation of sugar beet (Beta vulgaris L.) genotypes for resistance against root rot caused by Sclerotium rolfsii. Mycopath, 9(1): 13-15.

Farr, D.F., Bills, G.F., Chamuris, G.P. and Rossman, A.Y. 1989. Fungi on Plants and Plant Products in the United States. American Phytopatholgical Society, St Paul, MN, p. 1252.

Fery, R.L. and Dukes Sr.,P.D. 2002. Southern blight (Sclerotium rolfsii Sacc.) of cowpea: yield-loss estimates and sources of resistance. Crop Protection, 21: 403-408.

Flores-Moctezuma, H.E., Montes-Belmont, R., Jimé nez-Pérez, A. and Nava-Juárez, R. 2006. Pathogenic diversity of Sclerotium rolfsii isolates from Mexico, and potential control of southern blight through solarization and organic amendments. Crop Protection, 25: 195-201.

Hammons, R.O. 1994. The origin and history of the groundnut. Pp. 24-42. In: The Groundnut Crop: A Scientific Basis for Improvement (Smartt, J., ed). Chapman \& Hall, London.

Harlton, C.E., Levesque, C.A. and Punja, Z.K. 1995. Genetic diversity in Sclerotium (Athelia) rolfsii and related species. Molecular Plant Pathology, 85 (10): 1269-1281.

Kolte, S.J. 1984. Diseases of Annual Edible Oilseed Crops. Vol. I. Peanut Diseases.CRC Press, Boca Raton, FL.

Lakpale, N., Khare, N. and Thrimurty, V.S. 2007. Suppression of Sclerotium rolfsii Sacc.: an intergrated approach. Soils and Crops, 17: 241-245.

Le, C.N. 2004.Study wilt diseases on groundnut and some methods to control them in Thua Thien 
Hue province. Vietnam National Journal of Plant Protection, 1: 9-15.

Le, C.N., Mendes, R., Kruijt, M. and Raaijmakers, J.M. 2012. Genetic and phenotypic diversity of Sclerotium rolfsii in groundnut fields in central Vietnam. Plant Disease, 96: 389-397.

Mehan, V.K., Mayee, C. D., McDonald, D., Ramakrishna, N. and Jayanthi, S. 1995. Resistance in groundnut to Sclerotium rolfsii caused stem and pod rots. International Journal of Pest Mangement, 41: 79-82.

Mehri, Z., Khodaparast, S.A. and Mousanejad, S. 2013. Genetic diversity in Sclerotium rolfsii population based on mycelia compatibility groups in Guilan province, Iran. Iranian Journal of Plant Pathology, 49 (3): 317-324.

Nguyen, T.N., Tran, V.M., Nguyen, T.T. and Le, C.N. 2004. Research on groundnut diseases in Quang Binh province. National Agricultural Rural Development,17: 337-342.

Punja, Z.K. 1985. The biology, ecology, and control of Sclerotium rolfsii. Annual Review of Phytopathology, 23: 97-127.

Punja, Z.K. and Jenkins, S.F. 1984. Influence of temperature, moisture, modified gaseous atmosphere, and depth in soil on eruptive sclerotial germination of Sclerotium rolfsii. Phytopathology, 74: 749-54.
Savage, G.P. and Keenan, J.I. 1994. The composition and nutritive value of groundnut kernels. Pp. 173-21. In: The Groundnut Crop: A Scientific Basis for Improvement (Smartt, J., ed). Chapman \& Hall, London.

Sennoi, R., Jogloy, S., Saksirirat, W. and Patanothai, A. 2010. Pathogenicity test of Sclerotium rolfsii, a causal agent of jrusalem artichoke (Helianthus tuberosus L.) stem rot. Asian Journal of Plant Science, 9(5): 281-284.

Toribio, J.A. and Rodriguez-Kabana, R. 1992. The effects of inoculum density and physical factors on the assessment of disease caused by Sclerotium rolfsii. Plant and Soil, 142: 107-112.

Yaqub, F. and Shahzad, S. 2005. Pathogencity of Sclerotium rolfsii on different crops and effect of inoculum density on colonization of mungbean and sunflower roots. Pakistan Journal of Botany, 37(1): 175-180.

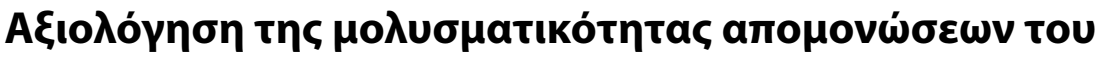

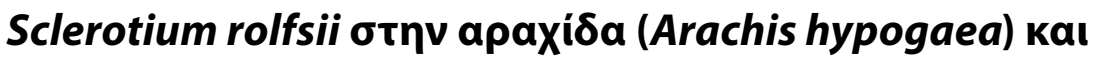

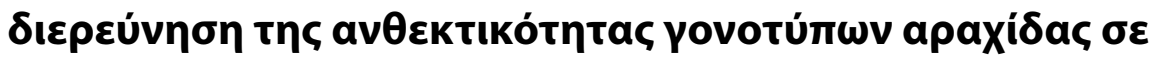

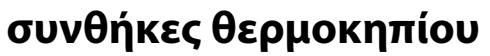

\author{
A.A. Eslami, S.A. Khodaparast, S. Mousanejad, F. Padasht Dehkaei
}

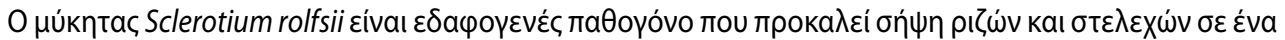

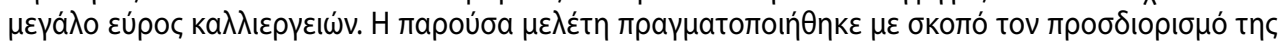

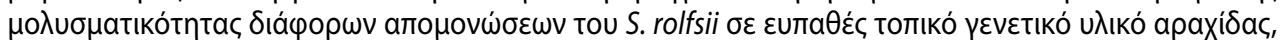

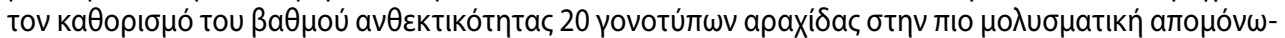

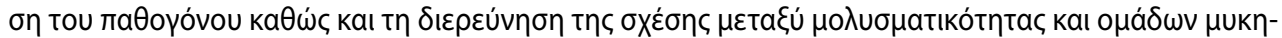

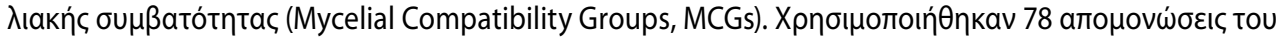

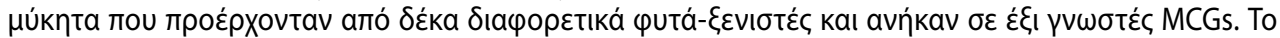

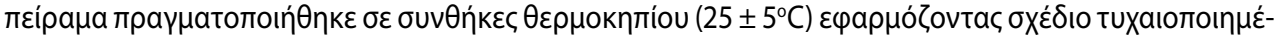

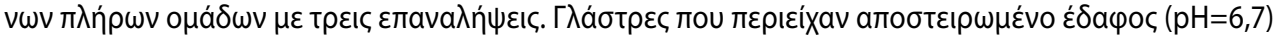

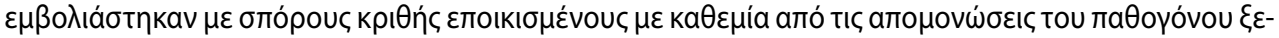
X

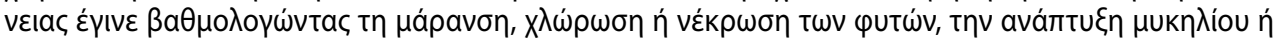

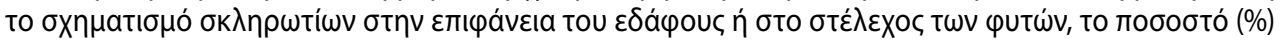

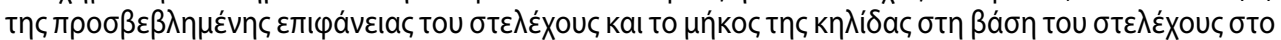

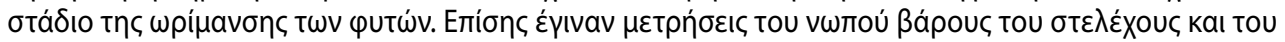

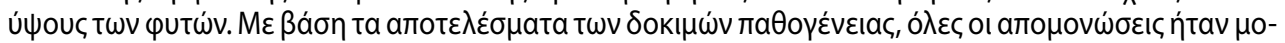




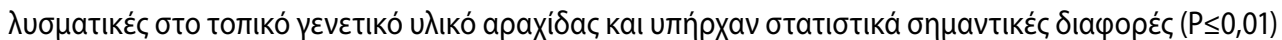

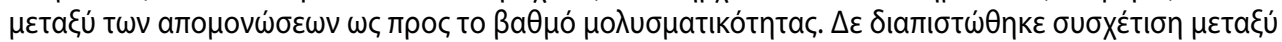

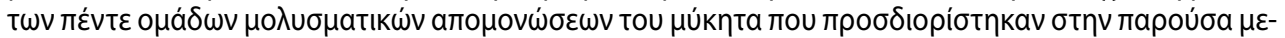

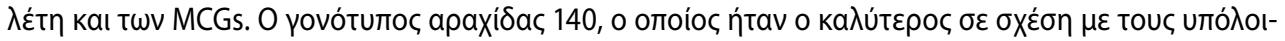

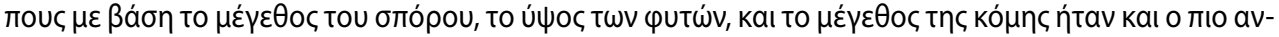

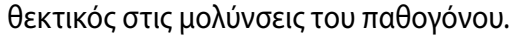

Hellenic Plant Protection Journal 8: 1-11, 2015 